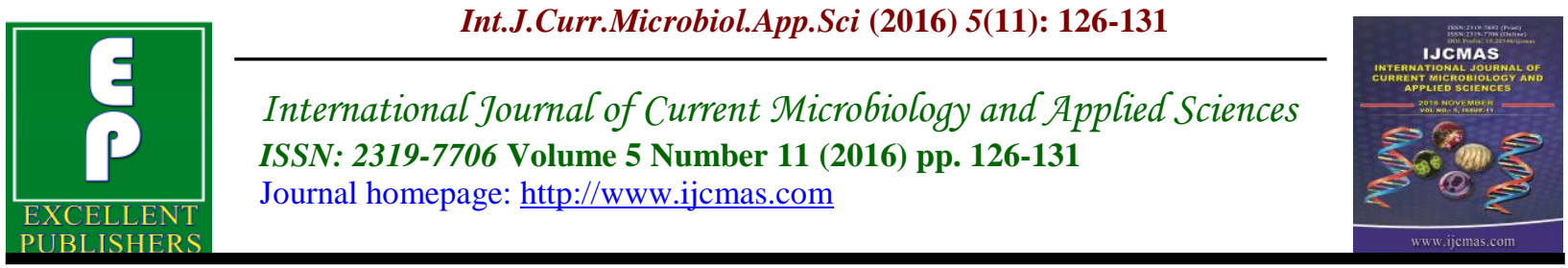

Original Research Article

http://dx.doi.org/10.20546/ijcmas.2016.511.014

\title{
Use of Plant Auxins Produced by Bacteria in Plant Tissue Culture and Seed Pre-treatment; A Possibility of Replacement of Synthetic Auxins
}

\author{
Kavita Bandivadekar*, Shruti Garge, Aditi Phand and Manjusha Bhave \\ M.K. BioFa Technologies Pvt Ltd, 70/21, The Synergy, Law College Road, \\ Pune, MS, India-411004 \\ *Corresponding author
}

A B S T R A C T

Keywords

IAA,

IBA,

auxins,

Phytohormones, multiplication, chick pea.

\section{Article Info}

Accepted:

04 October 2016

Available Online:

10 November 2016
With the objective to investigate the possible use of bacterial IAA, IBA in plant tissue culture as well as pre-treatment of legumes with or without Rhizobium this study is done. Bacterial isolates having characteristic production ability to produce Indole Acetic acid (IAA) and Indol Butyric acid (IBA) were isolated. Production of these two plant growth promoting substances (PGPS) is done and its effect on chick pea (Cicer arietinum) germination and tissue culture explants of Banana, turmeric, pineapple is done along with the standard synthetic IAA \& IBA. Bacterial PGPS have been evaluated along with commercially available PGPS like IAA, IBA, which are commonly used in plant tissue culture. Secondly, pre-treatment of seeds with bacterial IAA and/ IBA along with Rhizobium has been evaluated for growth response of the plant. MKB (Bacterial IBA, by MK BioFa isolate 13w) treatment along with Rhizobium showed maximum plant height, in Chick pea trial. In case of trials with Banana and Turmeric explants, shoot height, leaf number and leaf size increased remarkably with treatment of MKA as well as MKB. MKA, MKB treatment also favoured longer root length.

\section{Introduction}

Phyto-hormones or plant growth regulators are organic substances synthesized in defined organs of the plant that can be translocated to the other sites, where it triggers specific biochemical, physiological and morphological responses (Vamil, 2011). Today, the synthetic plant growth regulators are available commercially. If these chemicals are applied in specific quantity, enhance the plant growth (Naeem, 2004). There are five different types of plant growth promoting substances produced in plants. Out of this IAA, IBA are important as having major growth promoting activity. Many investigations showed that presowing treatment of growth regulators to the seeds could lead to increase in tissue hydration, redistribution of nutrient reserves, higher respiratory activities and enhancement of seedling growth, dry matter production, early flowering and yield. (Vamil, 2011). IAA exerts influence on plant growth by enlarging leaves and increasing photosynthetic activities in plants (Naeem, 2004). IAA also activates the translocation of carbohydrates during their 
synthesis (Naeem, 2004; Ritenour, 1996). It has been observed that IAA in combination with Kinetin caused a decrease in length and number of internodes, expansion of main stem diameter and increases the number and area of leaves (Naeem, 2004). In nature the microorganisms present in the rhizosphere of plant roots, help the plant by producing these plant growth promoting substances. Many of them are known to produce compounds like IAA, IBA, NAA (Naphthalene acetic acid) (Ali, 2007). Commercially available Phyto-hormones like IAA, IBA and NAA are commonly used in plant tissue culture. But bacterial Phytohormones have not been evaluated to replace these commercial synthetic preparations. Secondly, pre-treatment of seeds with bacterial IAA and/ IBA along with Rhizobium has not been evaluated for growth response of the plant. Chick pea is third most important legume in the world. In India no plant growth regulator is used in Chick pea growth. India is world leader in Chick pea production.

Bacterial production of IAA and its effect on plant growth has been reported by many researchers (Mohite, 2013; Ali, 2009). The main objective of the present study is to investigate the possible use of bacterial IAA, IBA in plant tissue culture as well as pretreatment of legume, especially Chick pea with or without Rhizobium.

\section{Materials and Methods}

\section{Bacterial strains}

Bacterial Strains were isolated from soil and preliminary screening was done by Solawaski reagent (Farah, 2005).

\section{Extraction of crude IAA/IBA}

From each isolate crude IAA and IBA was extracted. Single colony of each isolate was inoculated in $25 \mathrm{ml}$ nutrient broth supplied with $2,4,6 \& 8 \mathrm{mg} / \mathrm{ml}$ of tryptophan and incubated at room temp for 48 hrs. Bacterial cells were separated from the supernatant by centrifugation for $30 \mathrm{~min}$ at $6000 \mathrm{rpm}$. The separated supernatant was acidified to 2.5 $\mathrm{pH}$ with $1 \mathrm{~N} \mathrm{HCl}$ and extracted with ethyl acetate. Ethyl acetate fraction was evaporated on an evaporator plate at $40^{\circ} \mathrm{C}$. The extract is dissolved in ethyl acetate and kept at $-20^{\circ} \mathrm{C}$ till used. This is directly used for running Thin Layer Chromatography.

\section{Thin Layer Chromatography}

Ethyl acetate fractions were loaded on TLC plates (Silica gel 60 F254) and run in Npropanol: water (8:2) solvent. The bands were observed under UV light. Standard IAA, IBA, NAA, tryptophan samples were run along with test extracts.

Experiments with Chick pea: Seed germination and vegetative growth

Chick pea seeds (40 numbers for each conc.) were soaked in $50 \mathrm{ml}$ water with 1 to 15 ppm of final concentration of bacterial IAA \& IBA. They were allowed to sprout (kept at $30^{\circ} \mathrm{C}$ for $48 \mathrm{hrs}$.) after removing the water. Germination was observed and noted. Same seeds were sown in different pots to observe their growth.

\section{Effect of auxin along with Rhizobium}

For this the Rhizobium [Rhizobium is $\mathrm{M} \mathrm{K}$ $\mathrm{BioFa}$ isolate] was grown in YEM medium till bacterial count of $10^{12} \mathrm{cfu} / \mathrm{ml}$ is achieved. The seeds were treated with $10^{9}$ $\mathrm{cfu} / \mathrm{ml}$ concentration in sterile distilled water for about 6 hrs. After decanting seeds were tied in muslin cloth for germination.

After the plants were grown, measurement of height, number of leaves and branches, roots was done. 


\section{Use in Plant tissue culture}

Banana, turmeric explants were grown in MS media supplemented with 1 PPM bacterial IAA (MKA) \&/or IBA (MKB) along with the control of synthetic IAA (SynA) and IBA (SynB) for Banana. Turmeric is not supplied with Synthetic IAA/IBA, while doing tissue culture, so a control with no addition of synthetic auxin is taken for its experiment. These were supplemented in 4 bottles, each having 10 plants. Same procedure was followed for multiplication and rooting experiments. After 4 weeks the plants were removed from the bottle and the plant height, leaf number, leaf size, root number and root length were measured.

\section{Results and Discussion}

Isolation and screening of bacterial
isolates

Total of 151 soil bacterial isolates were

Fig.1 Pre-treatment of seeds with Synthetic IAA (Syn A), Synthetic IBA (Syn B), bacterial IAA ( MKA), bacterial IBA (MKB), Synthetic IAA with Rhizobium ( Syn A Rz), Synthetic IBA with Rhizobium ( Syn B Rz), MKA with Rhizobium ( MKA Rz) and MKB with Rhizobium ( MKB Rz)

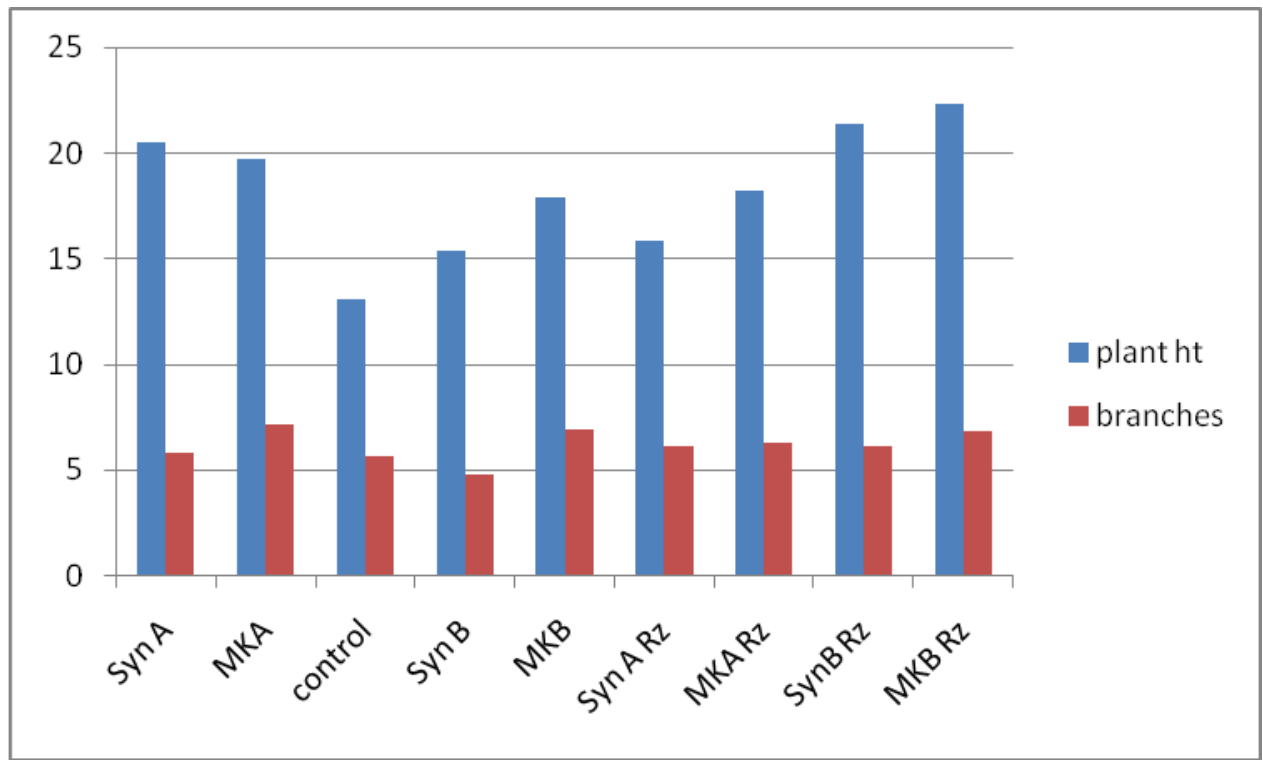


Fig.2 Vegetative growth of Banana explants. SynA and SynB are Synthetic IAA and IBA respectively. MKA is IAA produced by MK isolate $13 \mathrm{w}$ and MKB is IBA produced by MK isolate 14w. All are used in 1PPM concentration for treatment.

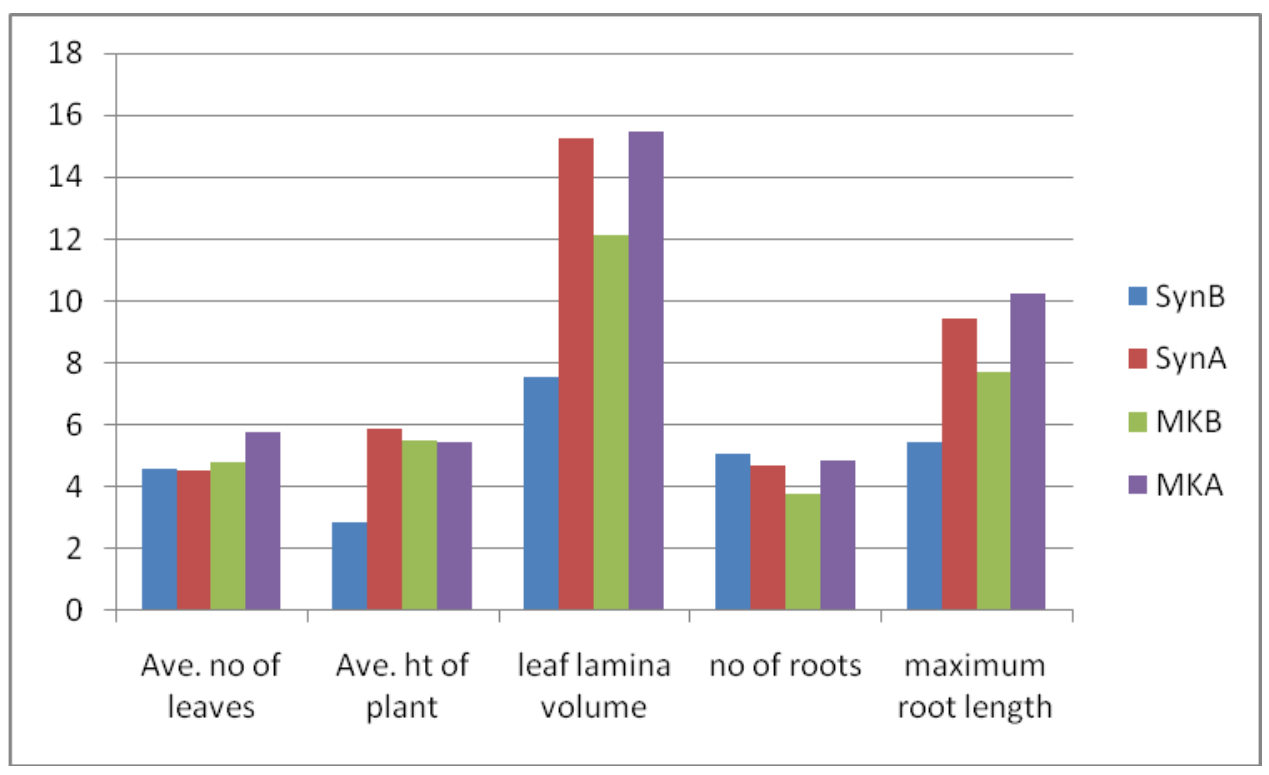

Fig.3 Shows individual roots of turmeric plants treated with MKA, MKB \& in control, no plant growth promoter substance provided

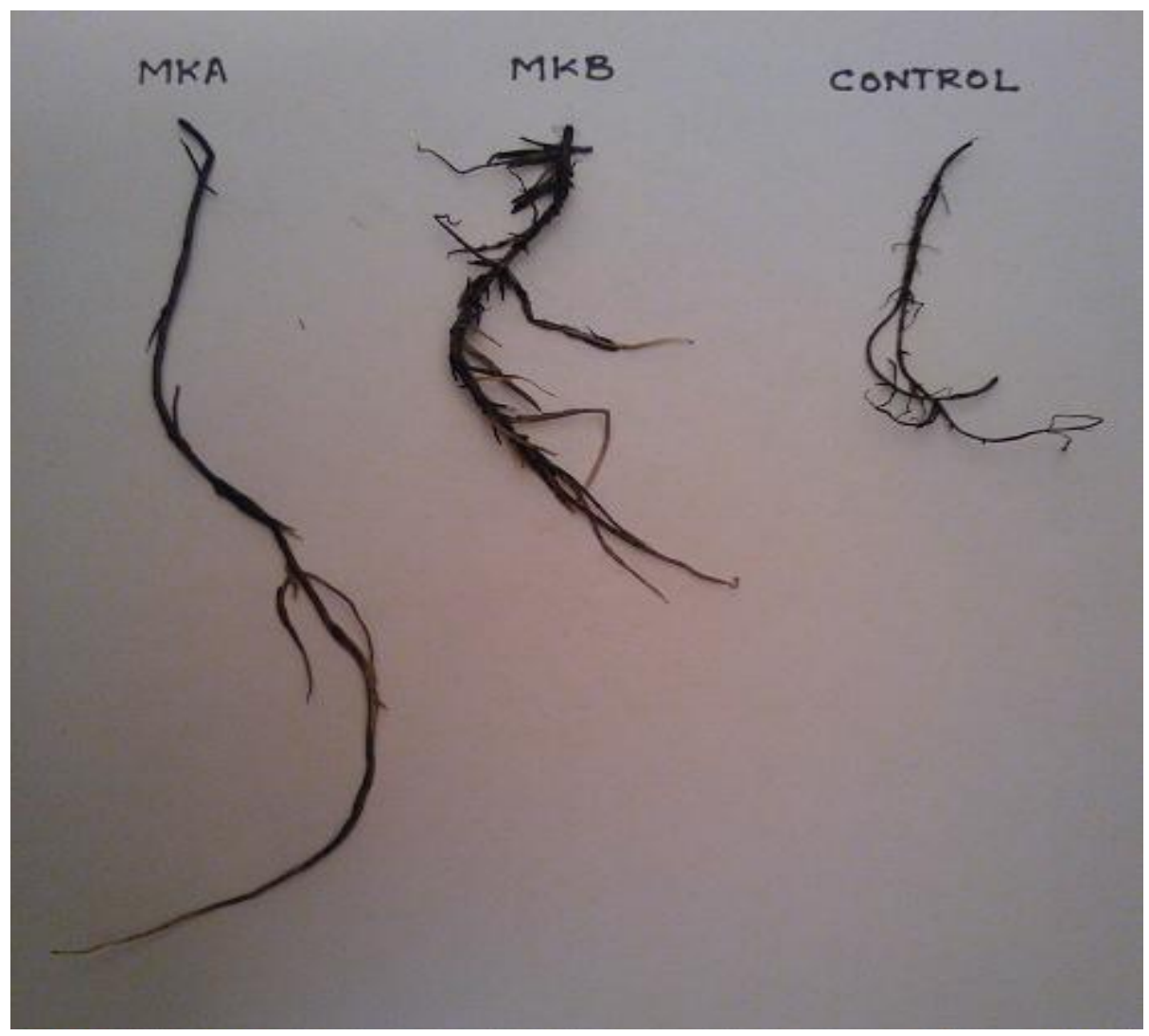


Fig.4 Turmeric multiplication: Turmeric explants were grown in 1 PPM MKA, MKB supplemented in MS medium and in control, no growth promoter was supplied.

Growth results after of 4 weeks.

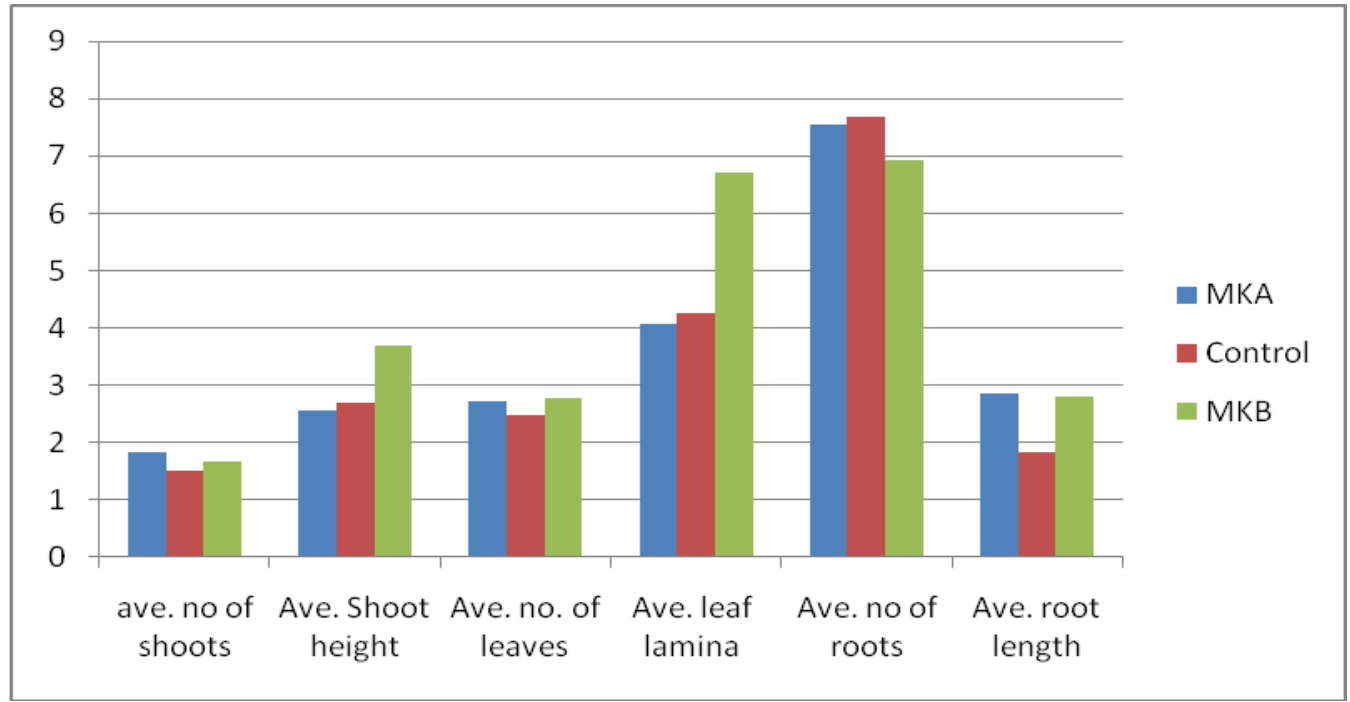

\section{Supplement in plant tissue culture}

Bacterial IAA/IBA is supplemented in MS medium while growing Banana and turmeric explants for rooting. The Syn A, Syn B, MKA and MKB were introduced in the bottles results are as follows:

\section{Experiments with Banana: Rooting}

The average number of roots is $3.4 \%$ more in case of treatment with MKA than SynA. The average root length is $41.57 \%$ more in case of MKB than Syn B and 8.38\% more in MKA than Syn A.

\section{Vegetative growth of Banana explants}

MKA showed production of more $(26.15 \%)$ number of leaves than Syn A. MKB showed $61.57 \%$ more leaf size than Syn B. It also gave rise to longer $(41.57 \%$ in $\mathrm{MKB}$ than Syn B) roots, and $8.38 \%$ more in case of MKA than Syn A. (fig 2)

\section{Turmeric rooting and multiplication}

The quality of roots with MKA and MKB was different than control. They looked healthier and had more diameter than the control. Length of the root was also more. MKB gave rise to more root branches than MKA and control.

The number of shoots coming out of explants is more in case of MKA (22\% more) \& MKB (11.33\% more) than control. Shoot height is also more $(37 \%)$ in case of MKB than control. Average leaf number increased marginally $(9.72 \% \& 12.55 \%$ for MKA and MKB resp.) With treatment of MKB the leaf size increased by $57.88 \%$. With treatment of MKA \& MKB the root length also increased by $56.60 \%$ \& $53.85 \%$ resp.

In conclusion, MKA \& MKB have shown similar or more enhancing effects as the commercial preparations of IAA and IBA for the general growth of the plant as evident from the experiments on Chick pea plant growth.

The MKA have also shown similar effect as commercial IAA used for induction of rooting in plant tissue culture. These two bacterial products are comparable with the 
commercial preparation and can replace the commercial synthetic products.

\section{References}

Ahmad, F., Ahmad, E., Khan, M.S. 2005. Indole Acetic Acid Production by the Indigenous Isolates of Azotobacter and Fluorescent Pseudomonas in the Presence and Absence of Tryptophan., Turk. J. Biol., 29: 29 -34

Ali, B., Hasnain, S. 2007. Potential of bacterial indoleacetic acid to induce adventitious shoots in plant tissue culture, Lett. Appl. Biol., 45: 128-133

Ali, B., Sabri, A.N., Ljung, K., Hasnain, S. 2009. auxin production by plant associated bacteria: impact on endogenous IAA content and growth of Triticum aestivum L. Lett. in Appl. Microbial., 48: 542 - 547

Mohite, B. 2013. Isolation and characterization of indole acetic acid
(IAA) producing bacteria from rhizospheric soil and its effect on plant growth, 13(3): 638-649.

Naeem, M., Bhatti, I., Ahmad, R.H., Yasin Ashraf, N. 2004. Effect of some growth hormones (GA3, IAA and kinetin) on the morphology and early or delayed initiation of Lentil (Lens culinaris medik) Pak. J. Bot., 36(4): 801-809.

Ritenour, M.A., Sutter, E.G., William, D.M., Saltveit, M.E. 1996. IAA content and auxiliary bud development in relation to russet spotting in harvested Iceberg lettuce. J. A. Soci.. Hort. Sci., 121(3): 543-547.

Vamil, R., Aniat-ul-haq, Agnihotri, R.K., Sharma, R. 2011. Effect of certain plant growth regulators on the seedling survival, biomass production and proline content of Bambusa arundinacea Science research reporter 1(2): 44- 48.

\section{How to cite this article:}

Kavita Bandivadekar, Shruti Garge, Aditi Phand and Manjusha Bhave. 2016. Use of Plant Auxins Produced by Bacteria in Plant Tissue Culture \& Seed Pre-treatment; A Possibility of Replacement of Synthetic Auxins. Int.J.Curr.Microbiol.App.Sci. 5(11): 126-131. doi: http://dx.doi.org/10.20546/ijcmas.2016.511.014 